\title{
Educação para a Cidadania Global no Brasil e a Participação do Imigrante
}

\begin{abstract}
Guilherme Perez Cabral
Professor titular (Categoria A1) da Pontifícia Universidade Católica de Campinas (PUC-Campinas). Membro do corpo docente permanente do Programa de Pós-Graduação Stricto Sensu em Direito (PPGD), vinculado à Linha de Pesquisa: Cooperação Internacional e Direitos Humanos. Doutor em Direito pela Universidade de São Paulo (2014), mestre em Direito pela Universidade Metodista de Piracicaba (2008) e graduado em Direito pela PUC-Campinas (2003). Integra o Banco de Avaliadores do Sistema Nacional de Avaliação da Educação Superior (Basis). Atua principalmente com os seguintes temas: Direito internacional dos direitos humanos, Direito à educação e Democracia. http://lattes.cnpq.br/9267585007227859. https://orcid.org/0000-0003-4480-3641. gpcabral@gmail.com
\end{abstract}

\section{RESUMO}

No cenário mundial globalizado, a construção da cidadania demanda sua compreensão para além do Estado soberano, incorporando, em seu conteúdo, outros povos e culturas. Debate-se, hoje, a cidadania global, oportunidade para repensar a cidadania no Brasil e a educação para sua efetivação, lidando com novos sujeitos de direito, com destaque, aqui, ao imigrante. Este artigo debruça-se sobre a Educação para a Cidadania Global (ECG), valendo-se de dois textos sobre o tema, elaborados pela Unesco, no âmbito da cooperação internacional para o desenvolvimento social: "Educação para a cidadania global: preparando alunos para os desafios do Século XXI" (2015) e "Educação para a cidadania global: tópicos e objetivos de aprendizagem" (2016). O artigo analisa-os em sua aplicação no contexto brasileiro, refletindo, especificamente, sobre a participação, em seu conteúdo normativo, da figura do imigrante. Por meio da análise de conteúdo dos textos citados, complementada pela revisão bibliográfica, começa apresentando conceitos centrais da ECG; depois, reflete sobre o contexto fático e jurídico brasileiro, em termos de cidadania e sua aprendizagem, bem como sobre o desafio da inclusão do imigrante; e, finalmente, a ECG é analisada em duas diretrizes: o direito à educação do imigrante e a contribuição dele na construção enriquecida da cidadania. Defende-se que, embora a cidadania constitua uma ideia pobre de sentidos no Brasil, cabe o debate sobre a ECG. Para tanto, a participação do imigrante, trazendo consigo seus valores, contextos e diferenças, é essencial.

Palavras-chave: Direitos humanos. Cooperação internacional. Educação. Cidadania global. Imigrante. Brasil.

\section{THE GLOBAL CITIZENSHIP EDUCATION IN BRAZIL AND THE IMMIGRANT'S PARTICIPATION}

\section{ABSTRACT}

In the context of globalization, the construction of citizenship's idea demands its understanding beyond the notion of the sovereign state. Their content must embody in itself other people and cultures. Nowadays, it is debated the global citizenship. This is an opportunity to rethink the citizenship in Brazil and the education for its effectiveness, dealing with new legal subjects. In highlight, here, the immigrant. This article focuses on Global citizenship education (GCE) and works with two documents wrote by Unesco, in the context of international cooperation for social development - "Global citizenship education: preparing learners for the challenges of the twenty-first century" (2015) and "Global citizenship education: topics and learning objectives" (2016). The article analyses the application of their concepts in Brazil. Specifically, it reflects on how the immigrant integrate the GCE's normative content. Methodologically, it is used the content analysis and the bibliographic review. In this way, the article begins by presenting central GCE's concepts. Then, it explores the Brazilian law and context, in terms of citizenship and the citizenship education, as well as the challenge of immigrant inclusion. Finally, it examines the GCE from the point of view of immigrant participation. It does this from two perspectives: the immigrant's right to education and its contribution to the enriched citizenship's learning. The article supports the position that, although the citizenship still has an emptied meaning in Brazil, it is important the debate on the GCE. Moreover, to do so, it is essential the immigrants involvement, bringing with them their values, contexts, and differences.

Keywords: Human rights. International cooperation. Global citizenship. Education. Immigrant. Brazil.

\section{SUMÁRIO}

1 Introdução. 2 Educação para a Cidadania Global. 3 A Educação para a Cidadania no Brasil e a Participação do Imigrante. 4 Educação para a Cidadania Global: Diretrizes à Participação do Imigrante. 5 Conclusão. 6 Referências. 


\section{INTRODUÇÃO}

Impregnada à figura do Estado-nação, a cidadania remete à participação nos processos de formação da vontade estatal e, sendo assim, no exercício do poder soberano nas sociedades democráticas. Sob a premissa da soberania popular, implica uma participação social efetiva, em igualdade de condições, de número cada vez maior de pessoas. Tudo isso sobre a base do reconhecimento dos direitos humanos fundamentais.

O olhar para o passado de lutas e conquistas em termos de direitos humanos e de democracia, compondo o conteúdo da cidadania, não permite o descuido de desvinculá-las de processos históricos de âmbito nacional. São construções sobre a base do Estado.

No caso brasileiro, as conquistas foram muito mais no plano normativo, no marco da Constituição Federal de 1988; direitos promulgados que contrastam com o cotidiano marcado pela cultura de profundo desrespeito aos direitos humanos e pela inexperiência democrática. Até 1988 não havia sido mais do que 60 anos de democracia formal, entrecortada por golpes de Estado e regimes autoritários. Daí não ser possível compreender a construção da cidadania, no país, com seus avanços e recuos, "sem uma visão do ontem. Sem a apreensão, em suas raízes, no caso brasileiro, de uma de suas mais fortes marcas, sempre presente e sempre disposta a florescer, nas idas e vindas do processo: a nossa inexperiência democrática" (FREIRE, 2011, p. 89).

A fragilização do Estado-nação, no cenário internacional globalizado, trazendo consigo o perigo de fragilização dos direitos humanos (SOUSA SANTOS, 2006) e da democracia em sua construção estatal, atinge em cheio tal concepção "tradicional" de cidadania, enfraquecendo o que, no Brasil, ainda é um projeto incipiente e inacabado.

A globalização é tomada especificamente como processo de interdependência e entrelaçamento econômico entre os diversos países. É sob este aspecto a configuração cosmopolita da produção e do consumo, por meio da exploração do mercado mundial: "No lugar da antiga reclusão e autossuficiência local e nacional, temos conexões em todas as direções, uma interdependência universal das nações" (MARX; ENGELS, 1998, p. 15).

Com a intensa internacionalização do processo produtivo e de movimentação descomprometida do capital financeiro, o poder soberano do Estado, tão reverenciado pela dogmática jurídica, somente no plano teorético, na idealização normativa, ainda determina, como força maior no território nacional, a produção jurídica e a organização social democrática, pois o Estado

(...) se transforma em mera província do capitalismo mundial, sem condições de realizar sua soberania (...) Um Estado-Nação em crise, amplamente determinado pelo jogo das forças produtivas predominantes em escala mundial, dispõe de escassas ou nulas condições para manifestar ou conquistar soberania (IANNI, 1999, p. 130).

Eis o contexto em que os problemas e conflitos sociais, sentidos individualmente e vividos localmente, assim como a busca de sua solução, passam, cada vez mais, a se articular com questões globais. Envolvem, nessa medida, um número maior de coletividades e de culturas, muito além das fronteiras do Estado. 
Daí a reflexão sobre a cidadania superar a minha comunidade, o meu Estado. Não cabe mais sua afirmação em detrimento dos outros: os excluídos do "nós", alvos de nossa propensão agressiva, contraponto facilitador da coesão de nosso agrupamento social. Com Freud, "Sempre é possível ligar um grande número de pessoas pelo amor, desde que restem outras para que se exteriorize a agressividade" (2011, p. 60).

O presente trabalho debate a educação para a cidadania nos termos do Pacto Internacional sobre Direitos Econômicos, Sociais e Culturais (1966), e a formação orientada ao fortalecimento do respeito aos direitos humanos e à capacitação de todos à participação social efetiva.

Debruça-se, nesse tema, sobre a inclusão de um sujeito específico: o imigrante. $O$ termo aqui é utilizado sem a preocupação de distingui-lo do refugiado, como faz, por exemplo, o Alto Comissariado das Nações Unidas para Refugiados (Acnur). O organismo prefere valer-se do termo imigração para se referir a um processo voluntário, diferentemente do refúgio, a envolver, nos termos do Estatuto dos Refugiados, "pessoas que estão fora de seus países de origem por fundados temores de perseguição, conflito, violência ou outras circunstâncias que perturbam seriamente a ordem pública" (ONU, 1967).

O artigo, então, faz, sim, uma distinção. Trata não do imigrante detentor de patrimônio e capital, produtor e consumidor, inserido nos processos econômicos globais, mas daqueles outros, muitos outros, marginalizados, desassistidos, os que ainda demandam dos Estados um suporte para uma vida digna. Falamos, assim, de categoria que confirma sua definição jurídica dada por exclusão: são os "outros", os não nacionais, "os demais indivíduos que se encontram em seu território" (ACCIOLY; CASELLA; NASCIMENTO E SILVA, 2016, p. 528). Imigrante é aquele que se estabelece "num Estado de que não é nacional", como prevê o artigo 2 da Convenção sobre a Proteção dos Direitos de Todos os Trabalhadores Migrantes e dos Membros das suas Famílias (ONU, 1990 ), não dispondo, nele, do direito humano fundamental de pertença (HABERMAS, 2012, p. 161). É, assim, excluído, de início, do status de cidadão.

No Brasil, não são poucos. Reconhecendo como traço característico da imigração a condição de "indocumentados" (BAENINGER, 2012, p. 9), os dados disponíveis indicam, por si só, fluxo importante de imigrantes pelo país. Apenas a título de exemplo, entre 2010 e 2016 foram registradas 93.202 solicitações de refúgio no país, e, desse total, a condição de refugiado somente foi reconhecida a 9.552 imigrantes (BRASIL, 2017, p. 5).

É no cenário de reconhecimento das limitações de uma execução de direitos humanos e democracia nos limites do território nacional, sem a consideração e em detrimento dos outros povos, que tem sido discutida a cidadania global.

Esta, afirma a Organização das Nações Unidas para a Educação, a Ciência e a Cultura (Unesco), "não implica uma situação legal" (UNESCO, 2015, p. 14), mas "um sentimento de pertencer a uma comunidade mais ampla e à humanidade comum, bem como de promover um 'olhar global', que vincula o local ao global". Traz, destarte, a concepção ativa e ampliada de cidadania, vinculada à participação efetiva nos processos sociais, enfatizando, agora, "a interdependência e a interconexão política, econômica, social e cultural entre os níveis local, nacional e global" (UNESCO, 2016, p. 14). 
O organismo especializado da Organização das Nações Unidas (ONU) tem atuado em prol da cooperação internacional em vista da consolidação da cidadania nestes moldes. Isso, por meio da educação para a cidadania global (ECG), modelo que "enfoca não apenas o que os estudantes aprendem, mas como aprendem - sobre si mesmos e outros, a fazer e interagir socialmente" (UNESCO, 2015, p. 18). Ocupa-se da construção de um conhecimento crítico a respeito das questões locais em conexão com os temas globais, orientado à práxis a partir de uma metodologia participativa, baseada em problemas experimentados cotidianamente. Tudo isso com a preocupação de promover valores e objetivos comuns, respeitando, ao mesmo tempo, as diferenças.

Sua visão sobre o tema está apresentada nos documentos: "Educação para a cidadania global: preparando alunos para os desafios do Século XXI" (2015) e "Educação para a cidadania global: tópicos e objetivos de aprendizagem" (2016).

O estágio da democracia e dos direitos humanos, no Brasil, em que o conceito de cidadania, em construção, claudica, sequer se efetivando em termos "nacionais", não autoriza, diante do cenário colocado, o alheamento deste debate. Nesse sentido, o objetivo do presente trabalho é analisar a noção ECG, conforme concebida pela Unesco, e sua aplicação no contexto brasileiro, debruçando-se, especificamente, sobre a participação, em seu conteúdo normativo (dever ser), da figura do imigrante.

Para tanto, valendo-se da análise do conteúdo dos textos citados, além da revisão bibliográfica sobre a temática, o artigo começa com a apresentação de conceitos centrais da ECG. Na sequência, debruça-se sobre o contexto fático e jurídico brasileiro, em termos de cidadania e sua aprendizagem, a partir da própria inexperiência, assim como sobre o desafio da inclusão do imigrante neste debate. Finalmente, a ECG, sob a ótica da participação do imigrante, é analisada a partir de duas diretrizes: i) a efetividade do direito à educação; e ii) sua contribuição fundamental na construção de uma cidadania para além dos estritos limites territoriais.

A posição, aqui defendida, é no sentido de que, embora a cidadania, em sua configuração jurídico-estatal, ainda constitua uma ideia muito pobre de sentidos no Brasil, cabe, sim, o debate sobre a ECG. Para esta, a participação do imigrante, trazendo consigo seus valores, conceitos, contextos e diferenças, é essencial.

\section{EDUCAÇÃO PARA A CIDADANIA GLOBAL}

Os textos a respeito da ECG elaborados pela Unesco não constituem normas com força jurídica vinculante aos Estados; contribuem, de qualquer forma, no âmbito da cooperação internacional para o desenvolvimento social e para a construção do sentido normativo (dever ser) do direito à educação afirmado pelo Direito Internacional dos Direitos Humanos; permitem o preencher de significação, em termos de experiências, métodos, instrumentos e procedimentos que podem abranger.

A ECG almeja possibilitar aos alunos o engajamento e assunção de papéis ativos nas esferas local e global, habilitando-o, como cidadão, ao enfrentamento e solução de problemas não apenas localizados, mas globais, contribuindo para "um mundo mais justo, pacífico, tolerante, inclusivo, seguro e sustentável" (UNESCO, 2015, p. 15). 
A Educação para a Cidadania Global envolve, para tanto, de acordo com o documento Educação para a cidadania global: tópicos e objetivos de aprendizagem, três dimensões conceituais básicas (UNESCO, 2016, p. 16):

i) dimensão cognitiva, da "Aquisição de conhecimento, compreensão e pensamento crítico sobre questões globais, regionais, nacionais e locais, bem como sobre as inter-relações e a interdependência dos diferentes países e grupos populacionais";

ii) dimensão socioemocional, a consolidar um "Sentimento de pertencer a uma humanidade comum, que compartilha valores, responsabilidades, empatia, solidariedade e respeito às diferenças e à diversidade"; e

iii) dimensão comportamental, no sentido da "Atuação efetiva e responsável, em âmbito local, nacional e global, por um mundo mais pacífico e sustentável".

Tais dimensões remetem a alguns objetivos próprios à ECG, enumerados no documento anterior, de 2015 (UNESCO, 2015, p. 16):

i) estímulo à análise crítica de questões atuais vividas pelos estudantes, identificando alternativas de solução. É a aprendizagem baseada em problemas, de acordo com a qual "alunos e educadores examinam as raízes e as causas de eventos e desenvolvimentos no âmbito local, consideram as conexões com o contexto global, e identificam possíveis soluções aos problemas identificados" (UNESCO, 2015, p. 15).

Trata-se de modelo muito próximo da filosofia educacional pragmatista de John Dewey. Para o autor, o processo educativo deve ter como escopo o desenvolvimento da capacidade e do hábito do pensar reflexivo, racional, compreendido como complexo processo de solução de dificuldades e conflitos vivenciados pelo sujeito (CABRAL, 2017a). Daí a proposta de uma educação baseada na solução de problemas que, extraídos das vivências dos educandos, causam-Ihe perplexidades, estimulando o exercício do pensamento, a ser continuamente lapidado.

Por isso, apresenta como um princípio educacional a ideia de que os conteúdos escolares devem, sempre, derivar das experiências (e dificuldades) de vida. A educação deve partir delas, de modo que "Tudo o que possa ser considerado como matéria de estudo (...) deve derivar de materiais que, originalmente, pertençam ao escopo da experiência comum cotidiana" (DEWEY, 2010, p. 75).

ii) Promoção do permanente reexame, pelos alunos, dos "pressupostos, visões de mundo e relações de poder em discursos oficiais" (científicos, políticos, etc.), de modo a se considerar grupos marginalizados e excluídos.

Nessa revisão de nossas verdades e preconceitos, a Antropologia, tão "acostumada a perguntas e relativizações", tem muito a contribuir com a ECG, pois o olhar antropológico, ensinam Bárbara Baptista e Roberto Kant de Lima, é "essencialmente marcado pelo estranhamento". Remete, complementam, a uma

(...) forma peculiar de ver o mundo e as suas interpretações, partindo sempre, necessariamente, de um surpreender-se com tudo aquilo que aos olhos dos outros parece natural. Relativizar categorias e conceitos e desconstruir verdades consagradas são, pois, importantes exercícios antropológicos (2014, p. 10). 
iii) Vinculada aos objetivos supracitados - a aprendizagem baseada em problemas e a permanente revisão de nossos pressupostos científicos, políticos e axiológicos - a educação para a práxis, propiciando o engajamento do aluno em ações individuais e coletivas em vista das mudanças pretendidas.

iv) finalmente, a educação para o reconhecimento e cooperação ampliada, envolvendo, para isso, as "múltiplas partes interessadas, incluindo aquelas que estão fora do ambiente de aprendizagem, na comunidade e na sociedade mais ampla" (UNESCO, 2015, p. 16).

Nesse ponto, emerge questão fundamental a perpassar em todo momento a ECG como direito humano fundamental: a promoção da universalidade, em termos de identificação de identidades, interesses, direitos e deveres comuns, respeitando-se, concomitantemente, as singularidades, as diferenças individuais e culturais (UNESCO, 2015, p. 18).

Trata-se, enfim, de um modelo educacional que se pretende transformador, promovendo:

(...) métodos ativos e participativos de aprendizagem, que engajam o aluno em pensamento crítico sobre questões globais complexas e no desenvolvimento de habilidades como comunicação, cooperação e solução de conflitos, a fim de resolver essas questões (UNESCO, 2015, p. 20).

O ambiente educacional, não se pode esquecer, porém, é um dado de uma realidade social maior, reproduzindo seus valores e estruturas historicamente conformadas. A introdução da ECG, nessa medida, é certamente um grande desafio. Ela busca a transformação das instituições sociais em favor de uma cidadania ampliada, a partir de dentro de sua própria revisão pelos sujeitos envolvidos. Tarefa difícil. No caso brasileiro, não somente ingênuo, seria temerário ignorar o legado do nosso passado pesado a reviver em nossas instituições sociais (CABRAL, 2016).

\section{A EDUCAÇÃO PARA A CIDADANIA NO BRASIL E A PARTICIPAÇÃO DO IMI- GRANTE}

A história do Brasil vem marcada por autoritarismos e violências. É um país que "nasceu e cresceu dentro de condições negativas à experiência democrática" (FREIRE, 2011, p. 90). Depois de outras duas décadas de governo autoritário (a Ditadura Militar) vem a Constituição de 1988. Erige um Estado democrático de direito, amparado em vigoroso sistema de direitos humanos fundamentais na linha dos tratados internacionais sobre a matéria.

Hábitos democráticos e uma cultura de respeito aos direitos humanos, contudo, não se promulgam. Na sempre retomada poesia de Carlos Drummond de Andrade, "As leis não bastam. Os lírios não nascem da lei" (2012, p. 23). No nosso caso, o texto constitucional acaba arremessado no curso de um processo histórico em que a população não havia internalizado tais concepções, nem poderia, como vivência própria:

Somos inexperientes - para não dizer analfabetos - nessas coisas de democracia e direitos humanos (...) Eis o ponto de partida, portanto, legado do passado. É o que temos para começar. A aprendizagem da democracia e dos direitos humanos, a capacitação e habituação às práticas democráticas e respeito ao outro, será a partir dessa nossa incipiente experiência (nossa inexperiência, portanto) (CABRAL; PERUZZO; OLIVEIRA, 2017, p. 35). 
Daí a importância da educação para a cidadania e o preparo para o seu exercício. Está prevista no artigo 205 da Constituição Federal como objetivo da educação. Tal escopo é retomado na Lei de Diretrizes e Bases da Educação Nacional (n. 9.394/1996), e, ainda, ressalta-se, nas Diretrizes Nacionais para a Educação em Direitos Humanos - EDH (Resolução n. 1/2012 do Conselho Nacional de Educação).

Compreendendo os direitos humanos em todas as suas dimensões, a Resolução refere-se à EDH, eixo fundamental do direito à educação, ao "uso de concepções e práticas educativas fundadas nos Direitos Humanos e em seus processos de promoção, proteção, defesa e aplicação na vida cotidiana e cidadã" (artigo 2). Seu objetivo central é a "mudança e a transformação social" (artigo 3ํ). Isso, no sentido da "formação para a vida e para a convivência, no exercício cotidiano dos Direitos Humanos como forma de vida e de organização social, política, econômica e cultural nos níveis regionais, nacionais e planetário" (artigo 5ㅇ).

Traz, então, no Artigo 3으, inciso V, a "democracia na educação" como um de seus princípios, valorizando, pelo menos nesse plano, a organização e a participação democrática em todos os espaços educacionais como elemento fundamental para a formação do cidadão hábil à vivência democrática e ao respeito aos direitos humanos.

Tal perspectiva educacional ampliada e ativa é retomada no dispositivo seguinte. Estabelece, entre as dimensões da EDH, além da apreensão de conteúdos historicamente construídos sobre direitos humanos, em sua relação com os contextos internacional, nacional e local - no sentido da cidadania global, portanto -, o "desenvolvimento de processos metodológicos participativos e de construção coletiva" e o "fortalecimento de práticas individuais e sociais que gerem ações e instrumentos em favor da promoção, da proteção e da defesa dos direitos humanos, bem como da reparação das diferentes formas de violação de direitos" (Artigo 4으, incisos I, IV e V).

Em decorrência de nossa própria inexperiência democrática e de direitos humanos, é verdade, as alternativas experienciais da EDH são, no fim, restritas pelo próprio texto normativo. Não é desenvolvida, na Resolução, a reorganização dos espaços escolares com a gestão democrática do ensino. A EDH se dá, preponderantemente, no nível da inserção de conteúdos nas disciplinas que compõem a "grade" curricular: "Artigo 7ํ A inserção dos conhecimentos concernentes à Educação em Direitos Humanos na organização dos currículos da Educação Básica e da Educação Superior poderá ocorrer das seguintes formas: I - pela transversalidade, por meio de temas relacionados aos Direitos Humanos e tratados interdisciplinarmente; II - como um conteúdo específico de uma das disciplinas já existentes no currículo escolar; III - de maneira mista, ou seja, combinando transversalidade e disciplinaridade".

Eis, a despeito disso, o projeto normativo de educação para a construção da cidadania, enriquecido de conteúdo democrático e de direitos humanos fundamentais. Um projeto, diga-se, ainda inacabado, que não se efetiva, tal como planejado no âmbito do dever ser, pois a "democracia" brasileira segue, em sua incipiência, composta por cidadãos "menores", que mal sabem ler e escrever. De fato, o resultado da avaliação do Ensino Fundamental nacional (anos finais), de acordo com o Índice de Desenvolvimento da Educação Básica (Ideb), de 2015, revela que, de zero a dez, o índice obtido foi 4,5 (Inep). 
Não raro, vem o texto normativo e paramos por aí: "o dever ser é controlado e condenado ao que é (ser), ante a força dos fatos e da história" (CABRAL, 2017b, p. 347). O cumprimento da norma, a construção da cidadania, ainda que "nacional", da democracia e dos direitos humanos, se perdem na conformação dos sentidos do texto à realidade que o infirma e que se pretendia superar.

A questão torna-se muito mais sensível com o cenário destacado de globalização e fragilização do Estado nacional. A dimensão global dos problemas sociais e as coletividades nele envolvidas não podem ser olvidadas. A construção da cidadania não pode mais, pois, ser pensada no âmbito de unidade política estatal, em termos schmittianos. Lembrando, para Carl Schmitt a política remete à diferenciação amigo-inimigo, "o extremo grau de intensidade de uma união ou separação, de uma associação ou desassociação" (SCHMITT, 2008, p. 28). Dentro da unidade (o Estado) os cidadãos, amigos; fora dela, os inimigos:

Ele é precisamente o outro, o desconhecido e, para sua essência, basta que ele seja, em um sentido especialmente intenso, existencialmente algo diferente e desconhecido, de modo que, em caso extremo, sejam possíveis conflitos com ele, os quais não podem ser decididos nem através de uma normalização geral empreendida antecipadamente, nem através da sentença de um terceiro "não envolvido" e, destarte "imparcial" (SCHMITT, 2008, p. 28).

Por isso, a importância de se debater a cidadania e o preparo para seu exercício no contexto da cidadania global. Isso passa, necessariamente, pela inclusão do imigrante. Fala-se, aqui, menos de um desafio e mais de uma oportunidade.

Até o ano passado vigorava, no Brasil, o Estatuto do Estrangeiro (Lei n. 6.815/1980), elaborado durante a Ditadura Militar, tendo, entre suas diretrizes, as noções de "segurança nacional" e a "defesa do trabalhador nacional". Com efeito, previa no artigo 2o: "Na aplicação desta Lei atender-se-á precipuamente à segurança nacional, à organização institucional, aos interesses políticos, socioeconômicos e culturais do Brasil, bem assim à defesa do trabalhador nacional". O imigrante - nem todos, é verdade - era visto como uma possível ameaça à estabilidade, à ordem, à coesão nacional (OLIVEIRA, 2017, p. 171). Falando sobre o tratamento conferido ao estrangeiro, ainda sob a vigência da lei, assim resumiu Daisy Ventura:

(...) é fácil entrar no Brasil, mas é difícil aqui permanecer e trabalhar regularmente. Há direitos, mas são limitados e é difícil exercê-los. Ricos são bem-vindos, pobres bem menos. A sociedade valoriza muito seus antepassados imigrantes, mas raramente trata os imigrantes de hoje como gostaria que seus bisavós fossem tratados há décadas (2014).

Temos, agora, uma nova legislação: a Lei de Migração (n. 13.445/2017). Esta Lei busca, em sua gênese, promover uma "mudança de paradigma da legislação migratória brasileira". A imigração, "Até então considerada uma área subordinada aos temas de segurança nacional ou de controle documental do acesso a mercados de trabalho", passa, finalmente, a ser abordada sob a perspectiva dos Direitos Humanos". Trata-se, conclui-se, de "dívida histórica do Brasil para com os migrantes que são parte imprescindível da cultura e do desenvolvimento econômico de nosso país" (COMISSÃO DE ESPECIALISTAS, 2014, p. 6). 
Nesse sentido, estabelece, no artigo 3ำ, um conjunto de princípios da política migratória nacional, como a "universalidade, indivisibilidade e interdependência dos direitos humanos", o repúdio à discriminação, a "não criminalização da migração" e, destaca-se, a promoção de direitos, incluindo a "participação cidadã do migrante" e o acesso igualitário a serviços públicos, dentre os quais a educação.

No artigo 40 enumera uma série de direitos, ampliando os sujeitos de direitos humanos fundamentais no país. De fato, se o artigo 5o da Constituição, ao tratar dos direitos individuais e coletivos, assegura-os "aos brasileiros e aos estrangeiros residentes no país", o dispositivo em questão trata do "migrante", conceito muito mais amplo, estendendo a ele "em condição de igualdade com os nacionais, a inviolabilidade do direito à vida, à liberdade, à igualdade, à segurança e à propriedade", assim como a ele garantindo direitos humanos também em sua dimensão econômica e social, sublinhando-se, aqui, o direito à educação pública.

Eis um breve retrato do quadro jurídico brasileiro para a reflexão da educação para a cidadania global e a participação, nele, do imigrante; mais uma vez, não o que pode pagar pela sua inclusão, mas o que, vivendo à margem do mercado global de produção e consumo, é excluído do status de cidadão e de sujeito de direitos.

\section{EDUCAÇÃO PARA A CIDADANIA GLOBAL: DIRETRIZES À PARTICIPAÇÃO DO IMIGRANTE}

Em vista da participação do imigrante na concepção de ECG a partir das propostas da Unesco trazidas ao contexto nacional, apresentamos, aqui, duas diretrizes que consideramos fundamentais. Elas não esgotam a matéria, absolutamente, mas apenas, com sua pretensão de validade, abertura ao questionamento e razões aqui apresentadas, buscam contribuir para o debate crítico sobre o tema.

i) Inclusão do imigrante no ambiente educacional. Um direito humano fundamental. Como antecipado, o acesso igualitário e livre do migrante à educação está previsto como um dos princípios e diretrizes da política migratória brasileira (artigo 3o, inciso XI, Lei de Migração). O direito à educação consta, na sequência, expressamente, do artigo 4으, inciso $X$, de acordo com o qual há o "direito à educação pública, vedada a discriminação em razão da nacionalidade e da condição migratória".

Uma questão que surge, para a efetividade da norma, é a extensão do termo migrante. A lei, com a redação aprovada pelo Congresso Nacional, assim o definia no artigo 1ㅇ, § 1으, inciso I, considerando migrante a "pessoa que se desloca de país ou região geográfica ao território de outro país ou região geográfica, incluindo o imigrante, o emigrante, o residente fronteiriço e o apátrida". Incluía, destarte, o imigrante, definido, no inciso seguinte, seguindo o critério do estabelecimento (ou pretensão de) no território nacional, como "pessoa nacional de outro país ou apátrida que trabalha ou reside e se estabelece temporária ou definitivamente no Brasil".

O conceito legal de migrante foi, contudo, vetado. Os motivos do veto revelam concepção contrária ao escopo da lei, supramencionado, e uma interpretação desvirtuada da própria Constituição brasileira. Perde de vista normas fundamentais por ela estabelecidas, como a dignidade da pessoa humana, fundamento da República (Artigo 1으, inciso III), o objetivo desta 


\section{Humanos e}

Democracia

de construção de uma sociedade solidária que promova o bem de todos, sem discriminação (artigo 3o, incisos I e IV) e, como princípio a reger o país em suas relações internacionais, a prevalência dos direitos humanos (artigo 4으, inciso II). Justificou o presidente da República, Michel Temer:

O dispositivo estabelece conceito demasiadamente amplo de migrante (...) o que estende a todo e qualquer estrangeiro, qualquer que seja sua condição migratória, a igualdade com os nacionais, violando a Constituição em seu artigo 5 o, que estabelece que aquela igualdade é limitada e tem como critério para sua efetividade a residência do estrangeiro no território nacional.

Estender direitos humanos, além daqueles expressamente positivados no texto constitucional, para a Presidência da República, o violaria. Isso, olvidando - temerária ou, apenas, propositalmente - a expansividade já admitida para ficar no referido artigo 5으, em seu $§ 2$ : "Os direitos e garantias expressos nesta Constituição não excluem outros decorrentes do regime e dos princípios por ela adotados, ou dos tratados internacionais em que a República Federativa do Brasil seja parte".

Rememora-se que, tratando de tal expansividade no âmbito da criação de novos direitos fundamentais (e não em relação aos destinatários), Ingo Sarlet segue, em princípio, a mesma linha. Posiciona-se no sentido de que a tradição de nosso direito constitucional:

(...) aponta para uma exclusão da legislação infraconstitucional como fonte de direitos materialmente fundamentais, até mesmo pelo fato de nunca ter havido qualquer referência à lei nos dispositivos que consagram a abertura de nosso catálogo de direitos, de tal sorte que nos posicionamos, em princípio, pela inadmissibilidade dessa espécie de direitos fundamentais em nossa ordem constitucional (SARLET; MARINONI; MITIDIERO, 2016, p. 326).

A despeito desse entendimento, ressalta, por outro lado, que "não nos parece de todo desarrazoado uma interpretação de cunho extensivo que venha a admitir uma abertura do catálogo dos direitos fundamentais também de posições jurídicas reveladas, expressamente, antes, pela legislação infraconstitucional" (SARLET; MARINONI; MITIDIERO, 2016, p. 326)

De qualquer forma, à luz de interpretação sistemática do texto legal, amparada pelas normas constitucionais referidas, o veto não implica a restrição do direito do imigrante à educação pública. A exclusão da definição legal de migrante não autoriza tal descaracterização da legislação.

Nesse sentido, importa mencionar o Parecer Consultivo no 21/2014 da Corte Interamericana de Direitos Humanos, solicitado pelos membros do Mercosul - incluindo o Brasil - sobre os direitos e garantias de crianças no contexto da migração.

Indagam os solicitantes a respeito das obrigações dos Estados com relação às medidas passíveis de serem adotadas a respeito de crianças imigrantes à luz do sistema americano de direitos humanos. Em resposta, retomando o que está expresso nos documentos internacionais (mas, também, nos nacionais), posiciona-se a Corte Interamericana de Direitos Humanos: 
(...) os Estados devem priorizar o enfoque dos direitos humanos desde uma perspectiva que tenha em consideração, de forma transversal, os direitos das crianças e, em particular, sua proteção e desenvolvimento integral, os quais devem prevalecer sobre qualquer consideração da nacionalidade ou status migratório, a fim de assegurar a plena vigência de seus direitos (destaque nosso) (2014, p. 105).

Dentre esses direitos, a serem assegurados independentemente de "qualquer consideração da nacionalidade ou status migratório", aparece a educação. É necessário, complementa a Corte, que o Estado receptor avalie, por meio de "procedimentos adequados que permitam determinar de forma individualizada o interesse superior da criança em cada caso concreto, a necessidade e pertinência de adotar medidas de proteção integral". Dentre outras, as que "assegurem o pleno acesso à educação em condições de igualdade" (2014, p. 39-40).

O referido parecer constitui, ademais, um dos fundamentos de recente decisão do Tribunal de Justiça do Estado de Roraima em relação aos direitos humanos das crianças imigrantes venezuelanas que se encontram no Brasil em estado de vulnerabilidade, mesmo que indocumentadas. Atribuindo força vinculante à manifestação da Corte, declarou como dever do Estado brasileiro retirar das ruas e assegurar proteção a crianças venezuelanas imigrantes, não cabendo, no caso, por se tratar de núcleo mínimo de direitos fundamentais - a abranger o direito à educação -, a alegação de restrições orçamentárias (2017).

Enfim, inclusão do imigrante, no sistema escolar, mesmo que sua situação ainda não esteja regularizada, efetiva um direito humano fundamental.

Trata-se, importa lembrar, de assunto regulamentado na legislação estadual de São Paulo desde 1995. Falamos da Resolução da Secretaria de Educação n. 10, de 2 de fevereiro de 1995. Dispõe sobre a matrícula de aluno estrangeiro na rede estadual de Ensino Fundamental e Médio, considerando, para tanto, a "necessidade de impedir qualquer tipo de discriminação entre criança brasileira e estrangeira documentada ou não" e "de se estabelecerem todos os direitos de crianças e adolescentes à educação nas escolas públicas, independentemente de sua nacionalidade ou documentação" (SECRETARIA..., 1995).

Afastando, destarte, a aplicação do artigo 48 do então vigente Estatuto do Estrangeiro, de acordo com o qual a "matrícula em estabelecimento de ensino de qualquer grau, só se efetivará se o mesmo estiver devidamente registrado", prevê que "As escolas estaduais que ministram o ensino fundamental e médio deverão receber os pedidos de matrícula dos alunos estrangeiros" (artigo 1ㅇ), havendo a Direção da Escola de "proceder à matrícula dos alunos estrangeiros sem qualquer discriminação" (artigo $2^{\circ}$ ).

Observa, contudo, Tatiana Chang Waldman que, no âmbito estadual, as dificuldades não se esgotaram com a vigência da Resolução, não deixando mesmo de existir posições que advogam pela aplicação dos dispositivos do Estatuto do Estrangeiro, questionando o acesso à educação por parte de imigrantes em situação irregular no país (2012, p. 178). Enumera, nessa linha, questionamentos e debates posteriores a respeito da inclusão do imigrante.

Nesse sentido, o Parecer n. 786/1995 do Conselho Estadual de Educação (CEE/SP), no qual se enfrenta a questão da extensão às escolas municipais e particulares não alcançadas pela Resolução, acabam dando tratamento diferenciado ao assunto. 
Também há o Parecer CEE/SP no 445/1997, no qual se responde à consulta de Delegacia de Ensino envolvendo o exame da compatibilidade entre a Resolução e o Estatuto do Estrangeiro (artigo 48).

Na sua fundamentação reitera-se "a necessidade de impedir qualquer tipo de discriminação entre criança brasileira e estrangeira, documentada ou não", transcrevendo-se, então, entendimento paradigmático da conselheira Neide Cruz sobre o tema:

Uma vez aceita a tese de que a matrícula é o ato pelo qual se concretizam as garantias de igual acesso à educação e permanência na escola, qualquer exigência ou diferença de tratamento que não seja de caráter pedagógico, ou que não vise adaptar o aluno ao currículo estabelecido, não diz respeito à função que deve ser cumprida pela instituição escolar. A escola não deve ser um local onde os registros escolares ou a documentação de alunos sirvam de pretexto para qualquer tipo de controle ou fiscalização a ser exercida sobre seus pais, sejam eles brasileiros ou estrangeiros. Exigir que as escolas comuniquem ao Ministério da Justiça as matrículas de alunos estrangeiros, bem como as alterações havidas em seus registros escolares, indica flagrante discriminação entre crianças e adolescentes brasileiros e estrangeiros (SÃO PAULO, 1997).

Assim afirmado, o direito humano fundamental à educação constitui elemento fundamental da formação para a cidadania global. Traz o outro para o ambiente escolar, reconhecendo-o como parte dele, e, a partir daí, consolidando uma aprendizagem num ambiente heterogêneo que viva cotidianamente a diferença e a interculturalidade.

Promove-se, assim, a dimensão socioemocional da ECG com a promoção daquele sentimento de pertença a uma "humanidade comum, que compartilha valores, responsabilidades, empatia, solidariedade e respeito às diferenças e à diversidade" (UNESCO, 2016, p. 16).

ii) A contribuição do imigrante na educação para a cidadania global. Não se trata, evidentemente, de um trazer o outro para o espaço educacional estranho, "tolerando" sua presença e o submetendo a processo educacional de aculturação, alheio à sua cultura, aos seus valores, aos seus conflitos e soluções.

O exercício do direito humano à educação, pelo imigrante, promovendo, nessa medida, sua cidadania, contribui para a educação nos termos propostos no âmbito da ECG. Noutros termos, tal experiência de cidadania promove (ou, pelo menos, pode promover), gradualmente, a cidadania global, oportunizando a "sensibilidade para a importância democrática das diferenças como vetor de integração" (DANELI; AQUINO, 2016, p. 25).

A aprendizagem baseada em problemas, efetivamente vivenciados pelos alunos, no âmbito de uma educação orientada à práxis, permite trazer, com a participação do aluno imigrante, além de outras perspectivas aos "nossos problemas", a compreensão e experiência de problemas locais de outros grupos. Ainda, a percepção e busca de soluções aos problemas globais de outras perspectivas locais.

Todas as dimensões e todos os objetivos da ECG são abrangidos a partir dessa convivência e experiência de reconhecimento.

Além da dimensão socioemocional, abarca-se a dimensão cognitiva, pois contribui com o conhecimento crítico das questões globais e locais em suas inter-relações com outros grupos populacionais. 
Nesse ponto, a aplicação da lei, garantindo-se o direito do imigrante à educação, faz do reexame de nossos discursos oficiais, repleto de preconceitos e ignorância em relação a outros grupos marginalizados, uma necessidade prática imediata; faz do estranhamento antropológico uma vivência cotidiana.

Ademais, promove-se a dimensão comportamental, com a atuação efetiva e responsável na compreensão e busca de solução aos problemas que, ainda que apenas local, podem já ser vistos em uma perspectiva intercultural.

Contribui, assim, com uma educação para a práxis da cidadania global, por exigir a vivência da diferença no dia a dia, envolvendo outras culturas para a solução dos problemas identificados e efetivação de mudanças pretendidas. Exige, por fim, a reflexão e busca de interesses e valores comuns, apesar das diferenças.

Em suma, é uma educação para a cidadania global na medida em que, num processo gradual e continuado, a pratica, estimulando "as pessoas a se abrir para diferentes culturas, bem como a pensar, agir e conectar-se de forma mais ampla e de diferentes maneiras" (UNESCO, 2015, p. 18).

A ECG, nesta perspectiva, pode efetivar, em termos de legislação nacional, o preparo para a cidadania, constitucionalmente previsto e revigorado no cenário de globalização. Nesse sentido, a EDH, isto é, a formação transformadora, na prática cotidiana dos direitos humanos (e da democracia), para sua afirmação como forma de vida e de organização social, deve estar em todos os níveis de convivência, do local ao global.

\section{CONCLUSÃO}

Tem, sim, ares de idealismo ingênuo debater a cidadania global num país em que a inexperiência da democracia e a cultura de desrespeito aos direitos humanos é, ainda, fator que inibe a percepção e vivência mínima da cidadania "tradicional". Um país no qual os direitos em geral, sem força de institucionalização, confundem-se com privilégio, valendo-se como "reflexo direto e imediato dos interesses ou da força daqueles que se empenham em sua aplicação" (WEFFORT, 1984, p. 42).

Se, no Brasil, o reconhecimento, como ser humano, na plenitude de sua dignidade, do negro, da mulher, do homossexual, já é um desafio histórico-cultural, o que dizer do estrangeiro, o boliviano, o haitiano, o venezuelano, que tenta, aqui, uma vida minimamente digna, desacreditada em seu lugar.

A ECG aparece, todavia, apesar de tudo, como uma alternativa dentro das precárias possibilidades de nosso tempo. Vivemos num mundo em que não se mostra mais cabível salvo em uma dogmática jurídica que, se manter intacta, tem de virar as costas à realidade - a defesa de uma cidadania consolidada à sombra do Estado soberano em detrimento dos outros, não nacionais, inimigos.

Revisar, reconstruir os conteúdos, numa perspectiva global da cidadania ainda em construção, positivada em nosso direito, pode ser vista, também, como uma grande oportunidade. 
Não se nega, absolutamente, o poder das instituições sociais de que a escola é mais um fator a serviço da manutenção do status quo. Vale, entre nós, a constatação de que "com frequência escolas e salas de aula são resolutamente não democráticas. Professores frequentemente não estão muito conscientes de seus pressupostos e, dessa forma, perpetuam comportamentos ou crenças não transformadoras" (UNESCO, 2015, p. 20).

Por outro lado, não devemos, como afirmou Adorno, "sabotar" as possibilidades de transformação social (ADORNO, 2004, p. 132), ainda que por demais precárias. Não se pode negar os espaços e sentidos disponíveis, mesmo que restritos, amparados na legislação nacional e internacional para a prática da educação para a cidadania, ampliada e preenchida de significação, com as contribuições da interpretação enriquecida proposta pela Unesco de educação para a cidadania global.

\section{REFERÊNCIAS}

ACCIOLY, H.; CASELLA, P. B.; NASCIMENTO E SILVA G. E. do. Manual de direito internacional público. 22. ed. São Paulo: Saraiva, 2016.

ADORNO, T. W. Escritos sociológicos I. Tradução Agustín G. Ruiz. Madrid: Akal, 2004.

ACNUR. Alto Comissariado das Nações Unidas para Refugiados. "Refugiados e migrantes: perguntas frequentes". Disponível em: http://www.acnur.org/portugues/2016/03/22/refugiados-e-migrantes-perguntas-frequentes/. Acesso em: 29 mar. 2018.

ANDRADE, C. D. A rosa do povo. São Paulo: Cia das Letras, 2012.

BAENINGER, R. "O Brasil na rota das migrações latino-americanas”. In: BAENINGER, R. (org.). Imigração boliviana no Brasil. Campinas: Núcleo de Estudos de População-Nepo; Unicamp; Fapesp; CNPq; Unfpa, 2012.

BAPTISTA, B. G. L.; KANT DE LIMA, Roberto. "Como a antropologia pode contribuir para a pesquisa jurídica? Um desafio metodológico". Anuário Antropológico, v. 39, n. 1, p. 9-37, 2014.

BRASIL. CONGRESSO NACIONAL. Lei no 6.815 de 19 de agosto de 1980. Define a situação jurídica do estrangeiro no Brasil, cria o Conselho Nacional de Imigração. Brasília, 1980. Disponível em: http://www.planalto.gov.br/ ccivil_03/Leis/L6815impressao.htm. Acesso em: 25 jul. 2018.

BRASIL. Lei no 13.445 de 24 de maio de 2017. Institui a Lei de Migração. Brasília, 2017. Disponível em: http:// www.planalto.gov.br/ccivil_03/_Ato2015-2018/2017/Lei/L13445.htm\#art124. Acesso em: 25 jul. 2018.

BRASIL. Conselho Nacional de Educação. Resolução no 1 de 30 de maio de 2012. Estabelece Diretrizes Nacionais para a Educação em Direitos Humanos. Brasília, 2012. Disponível em: http://portal.mec.gov.br/dmdocuments/ rcp001_12.pdf. Acesso em: 25 jul. 2018.

BRASIL. Instituto Nacional de Pesquisas Educacionais Anísio Teixeira (INEP). Ideb - Resultados e metas. Acesso em: 28 mar. 2018. Disponível em: http://ideb.inep.gov.br/resultado/resultado/resultadoBrasil.seam?cid=1722171.

BRASIL. Ministério da Justiça e Segurança Pública. Refúgio em números. Brasília, 2017.

BRASIL. Tribunal de Justiça de Roraima. Agravo de instrumento no 0000.17.000167-1, 2017.

CABRAL, G. P. Educação na e para a democracia no Brasil: considerações a partir de J. Dewey e J. Habermas. Educação \& Sociedade, Campinas, v. 37, n. 136, p. 873-889, Set./2016.

CABRAL, G. P. Educação e Democracia: perspectiva emancipatória a partir da filosofia social de John Dewey. Revista Quaestio luris, Rio de Janeiro, v. 10, n. 2, p. 844-866, 2017a.

CABRAL, G. P. Educação para a democracia no Brasil: Fundamentação filosófica a partir de John Dewey e Jürgen Habermas. São Paulo: Alameda Casa Editorial, 2017b.

CABRAL, G. P.; PERUZZO, P. P.; OLIVEIRA, T. S. F. Educação jurídica como formação para a promoção dos direitos humanos. Revista Videre, v. 9, n. 17, p. 28-43, 10 semestre/2017.

COMISSÃO DE ESPECIALISTAS (Portaria no 2.162/13 do Ministério da Justiça). Anteprojeto de Lei de Migrações e promoção dos direitos dos Migrantes no Brasil. Brasília, 2014.

CORTE INTERAMERICANA DE DIREITOS HUMANOS. Parecer Consultivo OC no 21/14 - Direitos e garantias de crianças no contexto da migração e/ou em necessidade de proteção internacional (2014). 
DANELI, J. C.; AQUINO, S. R. F. Qual Educação para os Direitos Humanos? Revista Direitos Humanos e Democracia, ano 4, n. 8, p. 3-37, jul./dez. 2016.

DEWEY, J. Experiência e educação. Tradução Renata Gaspar. Petrópolis: Vozes, 2010.

FREIRE, P. Educação como prática de liberdade. 14. ed. Rio de Janeiro: Paz e Terra, 2011.

FREUD, S. O mal-estar na civilização. Tradução Paulo César de Souza. São Paulo: Cia das Letras, 2011.

HABERMAS, J. Direito e democracia: entre factibilidade e validade. Tradução Flávio Beno Siebeneichler. Rio de Janeiro: Tempo Brasileiro, 2012. Vol. 1.

IANNI, O. "Globalização e crise do Estado-Nação". Revista Estudos de Sociologia, v. 4, n. 6, p. 129-35, 1999.

MARX, K.; ENGELS, F. O manifesto comunista. Tradução Maria Lucia Como Rio de Janeiro: Paz e Terra, 1998.

ORGANIZAÇÃO DAS NAÇÕES UNIDAS. Protocolo de 1967 relativo ao Estatuto dos Refugiados. 1967. Disponível em: https://www.acnur.org/fileadmin/Documentos/portugues/BD_Legal/Instrumentos_Internacionais/Protocolo_de_1967.pdf. Acesso em: 19 dez. 2019.

ORGANIZAÇÃO DAS NAÇÕES UNIDAS. Convenção Internacional sobre a Proteção dos Direitos de Todos os Trabalhadores Migrantes e dos Membros das suas Familias. 1990. Disponível em: http://acnudh.org/wp-content/ uploads/2012/08/Conven\%C3\%A7\%C3\%A3o-Internacional-para-a-Prote\%C3\%A7\%C3\%A3o-dos-Direitos-Humanos-de-todos-os-Trabalhadores-Migrantes-e-Membros-de-suas-Fam\%C3\%ADlias.pdf. Acesso em: 19 dez. 2019.

SARLET, I. W. OLIVEIRA, A. T. R. "Nova lei brasileira de migração: avanços, desafios e ameaças". Revista Brasileira de Estudos da População, v. 34, n. 1, p. 171-180, 2017.

SÃO PAULO. Conselho Estadual de Educação. Parecer no 786/1995. Matrícula de aluno estrangeiro. São Paulo, 15/12/1995. Disponível em: http://iage.fclar.unesp.br/ceesp/cons_simples_listar.php?id_atos=55208\&acao=entrar. Acesso em: 25 jul. 2018.

SÃO PAULO. Conselho Estadual de Educação. Parecer no 445/1997. Solicita esclarecimentos sobre a Res. SE no 10/95. São Paulo, 24/10/1997. Disponível em: http://iage.fclar.unesp.br/ceesp/cons_simples_listar.php?id_ atos $=56331 \&$ acao=entrar. Acesso em: 25 jul. 2018.

SÃO PAULO. Secretaria de Educação. Resolução SE no 10 de 2 de fevereiro de 1995. Dispõe sobre matrícula de aluno estrangeiro na rede estadual de ensino fundamental e médio. São Paulo, 1997. Disponível em: http://siau. edunet.sp.gov.br/ItemLise/arquivos/10_1995.htm. Acesso em: 25 jul. 2018.

SARLET, I. W.; MARINONI, L. G.; MITIDIERO, D.; Curso de Direito Constitucional. São Paulo: Saraiva, 2016.

SCHMITT, C. O conceito de político. Tradução Geraldo de Carvalho. Belo Horizonte: Del Rey, 2008.

SOUSA SANTOS, B. A gramática do tempo. Para uma nova cultura política. São Paulo: Cortez, 2006.

UNESCO. Organização das Nações Unidas para a Educação, a Ciência e a Cultura. Educação para a cidadania global: preparando alunos para os desafios do Século XXI. Brasília: Unesco, 2015.

UNESCO. Organização das Nações Unidas para a Educação, a Ciência e a Cultura. Educação para a cidadania global: tópicos e objetivos de aprendizagem. Brasília: Unesco, 2016.

VENTURA, D. "Política migratória brasileira é obsoleta e dificulta vida de estrangeiros", UOL Notícias. Disponível em: https://noticias.uol.com.br/opiniao/coluna/2014/05/03/politica-migratoria-brasileira-deixa-estrangeiros-em-situacao-precaria.htm. Acesso em: 3 maio 2014.

WALDMAN, T. C. O acesso à educação escolar dos imigrantes em São Paulo: a trajetória de um direito. 2012. Dissertação (Mestrado em Direito) - Faculdade de Direito da Universidade de São Paulo, São Paulo, 2012.

WEFFORT, F. C. Por que democracia? São Paulo: Brasiliense, 1984. 